\title{
The impact of competitive intelligence on products and services innovation in organizations
}

\author{
Phathutshedzo Nemutanzhela \\ Faculty of Information and Communication Technology \\ Tshwane University of Technology (TUT) \\ Pretoria, South Africa
}

\author{
Tiko Iyamu \\ Faculty of Information and Communication Technology \\ Tshwane University of Technology (TUT) \\ Pretoria, South Africa
}

\begin{abstract}
This paper discusses the findings of the study that was aimed at establishing the effect of Competitive Intelligence, hereafter referred to as $\mathrm{CI}$, on product and service innovations. A literature study revealed that $\mathrm{CI}$ and innovation are widely studied subjects, but the impact of CI on innovation was not well documented. CI has been widely acclaimed as a panacea to a lot of organizational problems. The study aimed at establishing the impact of Competitive Intelligence (CI) on products and services Innovation in organisation. A case study was conducted, using an Information and communication technology (ICT) organisation. Innovation-decision process was applied in the data analysis. At the end of the study on the impact of competitive intelligence on products and services innovation in organisations the following was achieved. It was better understood that while CI is overemphasized as revolutionary, customer focused information systems products and services still remain challenging. It was also understood that not all organisations that deploy CI produce more innovative methods. A lack of knowledge- sharing and limitations within the organisational culture were found to be important factors for the deployment of competitive intelligence products and services in the organisations. Conclusions of the study basing on the findings are presented.
\end{abstract}

Keywords-Competitive Intelligence (CI); Diffusion of Innovation (DoI); Innovation; Product; Services.

\section{INTRODUCTION}

The ability to innovate is at the heart of every business' survival. When a business runs out of innovative capabilities, then it is bound to exit the fight to attain and keep customers. [1] Contends with this view that "for over 20 years, successful product innovation has been considered a key requirement for business success".

For innovation to realize its full value there is need for the market to buy the final product or service. This necessitates the innovating firm to gather as much knowledge as it can about the needs of the customer, or to create such a need in the market. This kind of creating a need is what [2] called the need pull model. In the need pull model the search for a high potential market initiates a search for the inside or outside the firm knowledge to develop an innovative product that would meet market a need. This is the usefulness of Competitive Intelligence to gather the required knowledge to create opportunity in the market.

Besides the firm creating a need, there are other needs that are created as a result of responses to the competition. [3] contends that "Competitive Intelligence units can also help a firm to understand how a rival has developed their own unique capabilities and asset caches, assess a rival's ability to imitate their strategy or assist a company to assess how to uniquely bundle resources to create value for its customers." This way a firm will reposition itself to respond with the situation in the competitive environment. This would be a direct impact of CI.

\section{LITERATURE REVIEW}

The study aimed to develop a framework for understanding the impact of competitive intelligence on products and services innovation in organisations. Related studies were reviewed, with consideration that this is a conference proceedings paper.

According to Cavalcanti [4] "The essence of intelligence begins with environmental scanning activities, also known as surveillance. The essence of this process is a transformation of data, information and knowledge into intelligence as a final product." However intelligence as a final product becomes useful if and when the final consumer's needs have been satisfactorily met.

Another value of Competitive Intelligence is the ability to gather consumer opinion. [4] Asserts that "Consumer opinion can offer insight into the benefits of a product or a service as well as consumption tendencies. It can also help identify wishes, dreams and future fantasies." These future fantasies are the heart of the innovative process. As soon as the organisation can gain insight of the wishes of the consumers, this will direct the innovations in an attempt to satisfy the consumer needs. The extent to which the organisations turn this information into a resource for product or service innovation is the reason of this study.

In the literature, it is customary make a distinction between (competitive) intelligence as a product and as a process (e.g., $[5,6$, and 7]). In treating intelligence as a product, authors refer to the "information" or "knowledge" obtained and used for strategic purposes. The process view stresses the process by means of which this information or knowledge is obtained. Both the above definitions stress the process aspect. The first definition also highlights intelligence as a product. If competitive intelligence is seen as a product, it is usually compared with data, information and knowledge [5, 6, and 7].

CI has two basic functions namely to move competitive losses to wins and move competitive pushes (no decisions) to 
wins [8]. [8] Asserts that "To achieve this kind of impact, Competitive Intelligence must address the core issues of departments that have influence on the drivers of competitive outcomes. Specifically, Competitive Intelligence needs to address mission critical issues for sales, marketing, and product development." The issue asserted here is the ability of the users of Competitive Intelligence to transform whatever information they have gathered into an innovative product or service. The best way it will address sales and marketing is providing an innovative product or service in addition to formulating a formidable strategy. Hence the purpose of the study was to establish how far CI contributes to the process of product and service innovation.

\section{A) CI in the process of products and services innovation}

According to some studies, innovation is not a single act but rather a process which begins with an idea or an invention $[9,10,11,12$, and 13]. The classification of Innovations into different types focuses attention on the outcomes of the innovation process which have been defined as a new product or service, a new production process technology, a new structure or administrative system or a new plan or program pertaining to organisational members [9].

The power of competitive intelligence to contribute to product and service innovation lies in its ability to enable technological forecasting, as [14] aptly titled their 1998 paper "Technological forecasting techniques and Competitive Intelligence: tools for improving the Innovation process". Their argument is that "Technological forecasting can be used as a tool to help the forecasters in the process of describing, in the most precise way possible; how a future machine will be; and its method of operation and its characteristics. In other words, how, where and what should be innovated." The information that serves as the intelligence is that information that is in the right hands.

Information with a touch of expertise makes a difference in the process of Innovation.

Frates and Seena's [15] argue that an important subset of competitive intelligence, competitor intelligence is insufficient, and potentially misleading. If all a company does is track known competitors within its own industry, it is likely to suffer from marketing myopia. This implies that a firm must not only focus on its competitors, but, more importantly, the whole general business environment. In essence the goal of CI is to facilitate a whole rounded body of knowledge that an organisation can draw from in its formulation of the Innovations it will present to the customer in form of goods and services.

However [15] do not explicitly show what impact CI would have on innovating for the new customers that they refer to. While they advocate targeting new customer segments, there is a need to enter these new markets with innovative products that will capture the markets.

\section{RESEARCH METHODOLOGY}

The study was descriptive because it was aimed at answering the question "what". Descriptive study "tries to discover answers to the questions who, what, when, where, and sometimes, how. The researcher attempts to describe or define a subject..." [16] The aim was to establish what are the impacts of Competitive Intelligence on product and service innovation in organization are. According to Cooper and Schindler [16] "qualitative refers to the meaning, the definition or analogy or model or metaphor charactering something, while quantitative assumes the meaning and refers to the measure of it." The research had a qualitative attribute because this allowed the researcher to gather perceptions and opinion about Competitive Intelligence. The quantitative view gathered the proportions of the practitioners of Competitive Intelligence and be able to generalize their opinion. Since the study collected opinion about the impact of Competitive Intelligence in the innovation process, these opinions were recorded as qualitative data because reference would be made about them in the form of quotes. These opinions were gathered through semi-structured interviews.

There were two main, primary and secondary sources used in the data collection, namely, interviews and document review, respectively. According to Leedy and Ormrod [17] data collection may be anything, such as electronic documents that can assist the researcher to answer a research question. Interviews were conducted with identified employees at Amajita. Relevant documents about the case study were gathered from authentic sources. This includes access to the organisation's strategy.

The semi-structured interview approach was used. According to Kvale [18], the most useful interview format for conducting qualitative research is often "semi-structured" (sometimes called "moderately scheduled"). A total number of 11 interviews were conducted. This number was reached heuristically, i.e., the decision to stop adding respondents was taken when nothing new was being learnt from the interviews. The research main question was: What are the impacts of IS innovation on CI products and services in organisations? There were subsidiary question to the main question.

\section{THEORY}

The Diffusion of innovations (DoI) theory was used in the analysis of the data. The notion of stages in an innovationdecision process conceptualized by [19] was employed. Therefore a model of the Innovation-decision process that covers five stages: Knowledge, persuasion, decision, implementation, and confirmation were used to gain knowledge and understanding of the impact of competitive intelligence on information systems innovation products and services in organisations. This was in order to develop a good information systems innovation framework.

The analysis was done at two different, macro and micro levels, individual and group, respectively. Each participant in the case studies was labelled as follows: in Amajita, as AJ_LA001 to AJ_LA011.

The Innovation decision process characterized as a process that occurs while individuals participate in a series of actions related to decisions [20] Knowledge occurs when individuals are aware of the Innovation and gain understanding of its functions. Persuasion is when individuals or decision-making units exhibit favourable or unfavourable behaviour toward the 
Innovation. Decision indicates when the individual or unit decides to adopt or reject the Innovation. Implementation occurs when the individual or unit decides to use the Innovation. Confirmation occurs when decision makers confirm or reject their decision to adopt the Innovation [20].

\section{DATA ANALYSIS}

Using the Innovation-Decision Process [19], the analysis of the data is presented as follows:

\section{A. Knowledge}

Knowledge was considered as key and a very important factor in the organisation. If the organisation is to remain competitive over time, the managers have to generally see a need to know more about new products and services, technology, and about current and potential competitors. One of the reasons that were attributed to the deployment of competitive intelligence (CI) is because the market keeps changing. Also information and communication technology keep changing and rapidly. Almost on daily basis, there are a new IS innovation products and services. According to one of the interviewees AJ_L002 (p8:99-100), the constant and rapid changing requires awareness by the employees and the employers, if the organisation is to have competitive advantage. AJ_LA004 (p20:277-278) also expressed that, the market trend of IS innovation products and service always changes. The way things are done changes every day because we are in the technology world. This challenge us; managers need to research further and make sure employees are always knowledgeable about products and services we offer so that we can remain competitive in the market.

Without the knowledge of the products and services the organisation won't be able to deploy CI. According to one of the of the interviewees AJ_LA001 (p4:37-38), we send our employees to boat camps, when our partner has initiated a new product and service so that they can be educated of the challenges faced during the implementation and also get to know the benefits that the innovation bring into the organisation.

According to one of the interviewees, AJ_L003 (p32: 475480), as an organisation, we face a challenge when employees are not aware of the products and services that are offered, because both the organisation and employees are impacted negatively. The costs of our business get affected and employee's growth is also affected. The employee further expressed that, Employees, who are not familiar with the environment they operate on, can be too reluctant and fearful to take on task. For fear of being exposed, which could lead to threat to their job, also some employees agrees or volunteer to take on task, which they lack the knowledge of, this results to poor quality of service delivery to the clients. This sometimes results in frustrations on the part of the informed employees and ultimately resignations. From the organisations point of view, these employees who lack knowledge were considered first when faced with retrenchments or dismissals.

\section{B. Persuasion}

Successful organisation consists of result-oriented persons. The capacity to achieve results consistently is tied to develop the ability to plan. Execute flawlessly, and follow-up consistently. Effective staffers require improving their personal effectiveness. It was necessary for each employee to convince themselves of the products and services. Thereafter, they could confidently implement and support the products and services on behalf of the organisation. According to one of the employees: I think as employees, we must first persuade ourselves on improving our personal effectiveness towards the deployment of CI before we can even question our managers on the measure they are putting in place to persuade us.(AJ_LA0010 p39:595-596). The employees further expressed that, even if employer put performance measure in place to persuade us, the performance will still be poor because we are not self-effective.

According to one of managers AJ_LA004 (p21:291-292), we have realized that if an employee is not ready to adopt the changes brought to them, their performance get affected as they don't become too involved in the deployment of that products and services, they even refrained themselves. For organisation to persuade employees to adopt the deployment of CI information systems products and service innovation is a challenge. This is mainly because each employee has his or her own view of how they see products and services. As such, many of the interviewees differ in their views and belief. The views and opinions were informed by individuals and groups roles in the deployment of CI in the organisation.

According to one of interviewees AJ_LA0011(p42:650651), Our organisation get the innovation from a global partner and it then gets implemented without finding out how we feel about the innovation, all that the organisation does is to send us to training so that we can be equipped on the deployment and benefits of products and services. Therefore employees were not given room for negotiation. Whatever that gets decided by the management, the employees have to comply with it. Not having a room for negotiations was a risk to the organisation, in terms of losing employees' commitment.

AJ_LA009 (p37:558-559) asserted that, Our skills are not measured, yet our managers give incentives for performance. It doesn't motivate many employees for them to put all your effort on a work that you know everyone will be rewarded the same regardless of the effort, but if the organisation had a measure in place, I believe all employees were going to strive for the best deployment. Performance management contract was required in order to develop a process for managing individuals and teams to achieve high levels of organisational performance.

\section{Decision}

According to AJ_LA001 (p1:9-10), We operate on a centralised environment, and the innovation to be deployed comes from our international partner who has already gone through the whole deployment. He further expressed that our organisation has to analyse the information of IS products and service to make sure it aligns with the strategy and culture of our business, before we can decide to adopt the innovation. Therefore many of the decisions made were based on objectives and strategy of the organisation. Analysis is vital in helping decision-makers understand how phenomena in the 
broader environment relate to their company's mission, objectives, and strategy.

AJ_LA001 (p4:38) mentioned that, We recognized the fact that organisations may lack the ability or means to respond or adapt to changes in the environment. This might be as a result of centralisation, which limits them innovative skills. Also the complexity and rapidity by which changes occurred had significant impact on the organisation's competitive challenges. As a result, an organisation's ability to receive or acquire information from the environment becomes an essential, yet not sufficient ingredient in the strategy formulation process. The partnership with an international company means the organisation was forced to adopt and deploy competitive intelligence in the exact way as the partners. This limits the organisation ability to decide on specific strategy. Decisionmaking to them, it just mostly means whether they decide to implement the product and services or not.

The operation of the organisation was centralised. Among other things, this was intended to ensure that there was uniformity of data in the organisation. AJ_LA007 (p32:480481) stated that, The business that we operate on is a centralised operation where all information is stored and retrieved from one central place called the "cloud" so everyone get in the organisation has access to this information which then makes it easy analysis the data and make decision.

\section{Implementation}

The organisation preferred to use the $\mathrm{CI}$ as the only source of inspiration and tend to be followers rather than leaders or innovators within specific markets. According to one of the employees AJ_LA007 (p30:439-400), Our organisation doesn't come up with innovation, but rather will follow the footsteps of our partners, which limit us from being creative and think strategically. AJ_LA006 (p28:417-418) stated that, It looks easy and simple to implement products and services which are already done somewhere, but as the organisation we face challenges of aligning the innovation with our own culture and strategy.

The implementation of CI products and services is influenced by many factors. The factors include: the negative attitudes of managers, the organisations corporate culture not being conducive for CI. In some cases, we the managers tend to think that we know it all. As a result, we fail to listen to advices from our colleagues, and believe whatever we decide on has to be implemented exactly that way, the time we realize it's wrong. The damage has been done and all the money used for implementation has been wasted (AJ_LA003 p11:79-80).

In the organisation, the implementation of $\mathrm{CI}$ was a challenge. This challenge was attributed to lack of strengths and weakness in context of skills, lack of resources such as infrastructure, and limited cost. According an interviewee, Like another competitive intelligence implementation, our organisation sometimes face challenges of not having enough resources, sometimes we try to cut implementation cost and end up missing the important steps of implementation (AJ_LA001 p3: 22-23).

AJ_LA002 (p10:92-93) Emphasizes on implementation being the most important stage on this organisation. The employees view implementation as the most important stage on competitive intelligence deployment. From strategy to the final deployment of CI, the organisation adopt a package from USA which already in use. Which then leaves them with the ability to only implement the product and service in the South African environment after adoption? The value that competitive intelligence add during the implementation process its cutting cost and time spent on it. Amajita achieve this by using CI tools that helps them better their services and product delivery.

\section{E. Confirmation}

The confirmation of CI products and services in the organisation was done on case by case. Competitive Intelligence implementation provides multiple tangible and intangible benefits to the organisation. However, the realisation of these benefits depends on how CI was implemented. According to one of employees: the acceptance of our products and services depend on how well we implement them, some of them get accepted well, and we see this through customers that organisation acquire after deployment (AJ_LA005 p23:314$315)$.

The most critical step towards the successful of a CI solution is an understanding of its users. One of the interviewees AJ_L009 (p36:546-547), questioned that if feasibility study was done accurately and all customer needs were understood before implementation, the organisation had faced less challenges to whether the customer will accept this new innovation.

After the implementation of CI on IS products and services innovation is done, the whole team awaits to see how the innovation will be accepted or confirmed as a success. The organisation also go through the own confirmation stage. We test our innovation and make sure everything is working according to the project plan (AJ_LA005 p15:359-360). Even though we have assurance that the innovation works, we still need a confirmation from our local customer to see if it works also for them (AJ_LA007 (p32:477- 478).

\section{FINDINGS}

From the analysis of the data, eight factors were found to be critical and influence the deployment of competitive intelligence products and services in the organisation. The factors include cultural values, knowledge sharing, environmental scanning, education and awareness, output, performance contract, centralisation and negotiation. These factors are discussed as follows:

\section{a) Cultural Values}

The arena of cultural values differs from one environment to the other. Within cultural settings, people share values about what is acceptable or not. In this sense, it is very rare for two organisations which are operating on two different continents to share the same cultural values. Within such context as Amajita find itself, this limits the creative skills of those who their organisation is not dominant. Therefore their culture and values are compromised to suit the deployment of CI products and services from another environment. But if this was not the case, the employees were going to contribute and explore in the meantime practicing and following their organisation cultural values. When cultural and values are compromised sometimes 
customer lack confidence on their organisational ability to deliver.

\section{b) Knowledge sharing}

Some of information, skills, knowledge and expertise are being shared in the organisation aimed to improve and sustain CI products and services. However, there are certain factors which the organisation hasn't addressed. This factors impacts on employee's willingness to share information. Such factors are performance contract, organisation perform on a centralized environment, and fear of losing their jobs if they share knowledge and skills they have. Their environment limits and forces the employees to restrain from sharing knowledge, as they lack measure to use for persuasion. Employees who have information that is worthy to the organisation, and refrain from sharing knowledge because of fear that they might lose their jobs. They also fear that their junior could use it to compete with them, and fear of losing power that they hold. Not being in position to innovate, was also another reason why employees don't share information that can help change the scope of the business of the organisation. They wait to be told what to do. Though, organisation has realized that knowledge constitutes a valuable intangible asset for creating and sustaining competitive advantages. Knowledge sharing activities were generally supported by knowledge management systems as adopted by the organisation. However, technology constitutes only one of the many factors that affect the sharing of knowledge in organisations. Others includedorganisational culture, trust, and incentives. The sharing of knowledge constitutes a major challenge in the field of knowledge management because some employees tend to resist sharing their knowledge with the rest of the organisation. And maybe if they have measure put in place this can persuade them to share information. However, trust goes with security, when employees don't feel secure at their organisation, they won't have trust. Personal interest will always supersede the interest of the organisation. As that continue to happens, no one will be will to share any of expertise that they have.

\section{c) Environmental scanning}

The organisation depends on their international partner for innovation, limiting them to exploit of CI tools. The organisation uses forms of workshops to check whether their clients could adopt the innovation which was presented to them by the international partner. Therefore the relationship they have built with their external customer plays a bigger role during environmental scanning. When there is new innovation, they act as quickly as possible. They should be able to realize the gap immediately. So that they can either adopt or reject the innovation. During that time they can utilize their customer as the tool to acquire information, instead of hosting events that can cost money and consume time. They have to use them as tool for finding of information about the environment and to check if the innovation can fit in. This enables the organisation to understand the external forces of change so that they may develop effective responses which secure or improve their position in the future. Environmental scanning had influence on the implementation of competitive intelligence products and services. As a result of the influence, some competitive intelligence products and services suffer rejection from potential customer. This is because the organisation didn't take time to scan the environment, however just implement.

\section{d) Education and Awareness}

Education and Awareness plays a significant role in encouraging and enhancing people's participation in the activities which were aimed and considered essential for achieving sustainable competitive intelligence products and services. The organisation seems to have less emphasis on educating their staff about the information systems products and services, particularly, the implementation process of the deployment of CI products and services. It seems as they just assume that all employees are aware of the deployment process. Employees who are not aware of the organisation they operate to, they are more of an expense, than an asset to the company. Because they won't even be able to transfer or acquire skills from each other as they don't have an idea of what's happening around their organisation. However, if the organisation can spend time educating and making employees aware of the CI deployment, they can cut cost and reduce time spent doing feasibility studies on the process of adopting and implementing innovation from outside partner.

\section{e) Output}

In order to improve the effectiveness and efficiency of CI products and services, the organisation must consist of result oriented persons. The capacity to achieve results consistently was tied to development of the ability to plan, execute flawlessly, and follow-up consistently. Unfortunately, many employees in the lacked the ability to plan as they only wait to be told what to do, instruction from the international partner. This inability to innovate affects their personal effectiveness. They can only execute innovation that has already been executed by the international partner. So they were not needed to be creative and plan positively. In majority of the cases, answers were provided to them. However, an organisation is required to improve their employee's personal effectiveness. Each personnel need to have a good understanding and motivating strategies competitive intelligence products and services in the organisation. Because an employee who fails do discipline themselves affects the performance of the company.

\section{f) Performance}

Organisation need to have contract that can sets out the terms of performance between the employees and the employer. Because the organisation doesn't have performance contract in place, employees seem to lack motivation, and this had impact on CI products and services. They don't trust colleagues with certain information, skills, knowledge and expertise they have. This also led to some employees not sharing information with some of their colleagues. Some of them even resigned because they feel that they are not secure. The performance contract builds relationship between employees and the employer. Because the rights and obligations of all parties involved in the performance were covered.

\section{g) Centralisation}

The activities of the organisation regarding planning decision-making they were concentrated within a particular group. The centralisation approach had impact on innovation of 
CI products and services in the organisation. When everything is centralised in the organisation, the organisation lacks skills to innovate. This means employee get to be told what to do. Employees don't have a view on the CI deployment but only to implement. The organisation force employees to reserve their input, because everything runs on a centralized space. Information and innovation comes from centre point, in most cases, from the international partner.

\section{h) Negotiation}

Employees don't have bargaining power. What employer decides on it goes. The nature of the business (centralised organisation) limit both employer and employees an opportunity to negotiate or come up with different views that could benefit the organisation. Even though the organisation is dominated by the global market, the culture and values they use are of the organisation. This put the employees on an uncomfortable situation where they are deploying a global innovation, yet the culture and values are not the same and still can't negotiate. If employees were given a chance to negotiate they could have had better way to deploy CI products and services, to suit the culture and values of the South African environment.

The above findings were interpreted and presented in the following section.

\section{Interpretation of the Findings}

The findings from the analysis are interpreted to be the factors which influence the innovation of competitive intelligence (CI) within the information systems environment. This is depicted in Figure 1 below. The discussions that follow explain the manifestation from these factors.

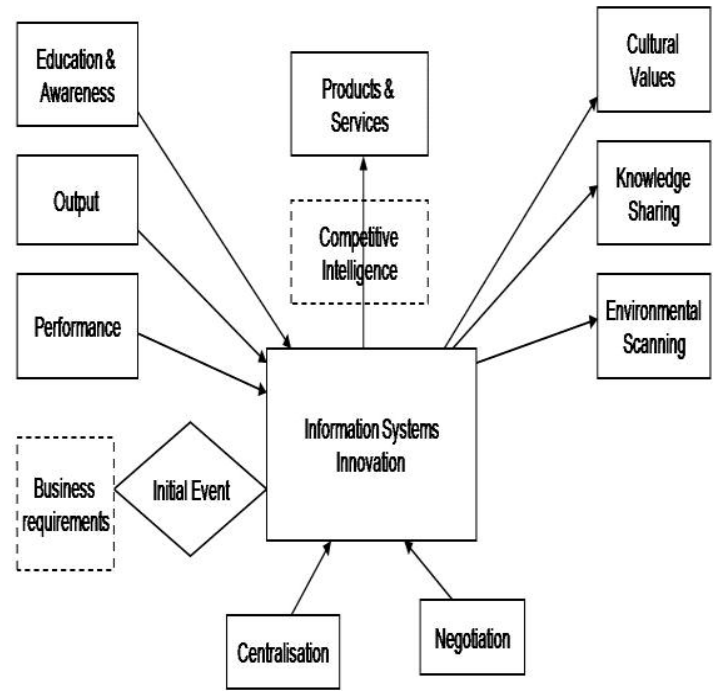

Figure 1. Factors Influencing Information Systems Innovation

a) Improvement - is a change in the thought process for doing something, and useful application of new inventions or discoveries. The organisation doesn't innovate but rather implement innovation, the environment and nature of the business that they operate in doesn't give them an opportunity to come up with innovation, or a discovery of any information systems products or services. When employees are not aware of the innovative process (products and services deployment) they become reluctant and lack innovative and creative thinking. The employees' acts, behaviour and performance manifest to the organisational performance. This has impact on skills and knowledge transfer.

b) Dominant - the international partner to Amajita was dominant in the innovation process. They are the one who comes up with innovation. It's their strategy, plans and execution that led to the deployment of the competitive intelligence, making them to be dominant party over Amajita. While the technology industry dominant technology and organisation cycles are faster than in many other organisations, the point is still that dominant organisations have to evolve or they will fail. Therefore, Global innovator should provide the full array of competencies needed by successful CI practitioners. Therefore Amajita leaders and managers must understand the significance of these sources in South African market, rather than agree to the naive concept that they get from their international partners as the market cannot be exactly the same.

c) Distribution - An organisation or set of organisations (go-betweens) involved in the process of making a product or service available for use or consumption by a consumer or business user. By sharing knowledge about products and services, employees gain more than they lose. Sharing knowledge is a synergistic process - you get more out than you put in.

d) Collaboration - is a process where two or more people or organisations work together to realise shared goals, (this is more than the intersection of common goals seen in cooperative ventures, but a deep, collective, determination to reach an identical objective). If you try to work alone - you are likely to fail - you need not only the input from other people but their support and buy-in. Being open with them; sharing with them, helps you achieve your objectives.

e) Reliance - employees might trust transferring skills to others, and know that the other employees and the organisation at large would benefit from it. They should also trust that the information won't be used against them tomorrow. Which means organisation has to assure them of security and that they job won't be at stake if they are willing to share information and expertise they have.

f) Involvement - is the state of a user in relation to a situation after that user has participated in the situation. It is, approximately, an internal analogue to aconflict of interest. Even with the low level of knowledge sharing that goes on today - if you do not make your knowledge productive than someone else with that same knowledge will. You can almost guarantee that whatever bright idea you have someone else somewhere in the organisation will be thinking along the same lines.

\section{CONCLUSION}

It was established that the role of Competitive Intelligence on product and service innovation was to inform strategic management, reflect customer needs, and inform rivals about the competitors and help firms locate themselves on the competitive scale. 
It was established Competitive Intelligence is overemphasized as revolutionary yet customers still remain unsatisfied by the services and products because most of Competitive Intelligence remains in talk, but not in execution. This was reflected by the numbers of respondents who said that Competitive Intelligence was not useful because what was collected was not used.

The findings and the analysis of the study indicate that further research relating to competitive intelligence can be conducted. Some of the suggestions are:

Organizational Culture - it would be in the interest of academic organisations to investigate and gain a better understanding of how organisational culture impacts on Competitive Intelligence products and services in organisations.

Underpinning theories - it would be a significant contribution to apply different theories such as Organisational information processing theory (OIPT) and TechnologyOrganisation-Environment Framework (TOT framework) in a similar study. Organisation need to be knowledgeable about the Competitive intelligence products and services they deploy so that they can make better decisions to innovate. Organisational information processing theory is applied to Organisations that need quality information to cope with environmental uncertainty and improve their decision making [21].

\section{REFERENCES}

[1] R. L. Chapman, C. E. O'mara, S. Ronchi S., A., M. Corso,. Continuous product innovation: a comparison of key elements across different contingency sets. Measuring Business Excellence. 2001 Pp 16-23. Available from www.emerald-library.com/ft [Accessed 10/08/2010]

[2] A. R. Burgelman, L. R. SAYLES. Transforming invention into innovation: the conceptualization stage in Burgelman A. R., christensen C. M., wheelwright S. C. 2004. Strategic management of technology and innovation 4Ed. McGraw Hill-Irwin Boston.

[3] S. Hughes. Competitive Intelligence as Competitive Advantage: The Theoretical Link between Competitive Intelligence, Strategy and Firm Performance. Journal of Competitive Intelligence and Management . Vol 3. No 3. Available at www.scip.org [Accessed 20/08/2010]

[4] P. E. Cavalcanti. The Relationship between Business Intelligence and Business Success Journal of Competitive Intelligence and Management .Vol 3. No 1 available at www.scip.org [Accessed 20/08/2010]

[5] L.M. Fuld. The New Competitor Intelligence. Chichester. UK: Wiley, 1995.

[6] L. Kahaner. Competitive Intelligence. New York: Touchstone, 1997.

[7] E. A. Philips, and D. Vriens. Business Intelligence. Deventer: Kluwer, 1999.
[8] R. B. Jeppsen. An introduction to impact-based Competitive Intelligence. 2005 www.scip.org [Accessed 16/ 05/10]

[9] F. Damanpour. Organizational innovation: a meta-analysis of effects of determinants and moderators. Acad. Mgmt. J.1991. pp.34:555.90.

[10] D. Dougherty, and E. Bowman. The effects of organizational downsizing on product innovation. California Management Review,1995. pp.37: 28-44.

[11] F. Drucker and F. Peter. The discipline of innovation, Harvard Business Review,80,(8). 2002. pp.77-83.

[12] Tidd, Joseph, Pavitt, Keith (contributor), Tidd, Joe, R. Bessant. ManagingInnovation : Integrating Technological, Market and Organizational Change, 2nd edition, John Wiley \& Son Ltd, UK. 2001.

[13] A. H. Van de ven, Polley, E. Douglas, Garud, Raghu, Venkataraman, Sankaran.The Innovation Journey, Oxford University Press, USA.2000.

[14] Â. D. Lemos, and A. C. Porto. Technological forecasting techniques and Competitive Intelligence: tools for improving the Innovation process Industrial Management \& Data Systems. 1998. pp7:330-337.

[15] J. Frates and S. Seena. Using Business Intelligence to Discover New Market Opportunities, Journal of Competitive Intelligence and Management, vol. 3, no. 2, 2005. available at www.scip.org [Accessed 20/03/2010]

[16] D. R. Cooper and P. S. Schindler. Business research methods 8th ed. McGraw Hill, Boston. 2003.

[17] P. D. Leedy and J. E. Ormrod. Practical research: planning and design. 8th ed.: Pearson. MAREE K., 2007. First steps in research. Pretoria: Van Schaik.2009.

[18] S. Kvale. Interviews: An introduction to qualitative research London: Sage.1996.

[19] E. M. Rogers. Diffusion of Innovations. 4th ed. New York: Free Press. 1995.

[20] E. M. Rogers. Diffusion of innovations (5th ed.). New York: Free Press. 2003.

[21] G. Premkumar, K. Ramamurthy and C. S. Saunders. Information processing view oforganisations: An exploratory examination of fit in the context of interorganisational relationships. Journal of Management Information Systems, 22(1), 2005.pp.257-294).

[22] Phathutshedzo Nemutanzhela and Tiko Iyamu; "A Framework for Enhancing the Information Systems Innovation: Using Competitive Intelligence".

\section{AUTHORS PROFILE}

Phathutshedzo Nemutanzhela has a Masters degree (MTech) Business Information Systems from Tshwane University of Technology. She has a Baccalaureus Technologies (BTech): Information Technology (Informatics). Her principle research interest is Competitive Intelligence, Information Systems and innovation. Theoretically, she focuses on Diffussion of Innovation (DoI) Theory.

Tiko Iyamu is a Professor of Information Systems at the Tshwane University of Technology, Pretoria. His research interests include Mobile Computing, Enterprise Architecture and Information Technology Strategy. Theoretically, he focuses on Actor Network Theory (ANT) and Structuration Theory (ST). Iyamu is author of numerous peer-reviewed journal and conference proceedings articles. 